Article

\title{
Optimization of Salix Carbonation Solid Acid Catalysts for One-Step Synthesis by Response Surface Method
}

\author{
Ping Lu ${ }^{1}$, Kebing Wang ${ }^{1, *}$ and Juhui Gong ${ }^{2}$ \\ 1 College of Science, Inner Mongolia Agricultural University, Huhhot 010018, China; 13643584686@163.com \\ 2 School of Chemistry and Chemical Engineering, Inner Mongolia University, Huhhot 010018, China; \\ imugongjuhui@163.com \\ * Correspondence: wkb0803@imau.edu.cn
}

Received: 16 March 2019; Accepted: 8 April 2019; Published: 12 April 2019

check for updates

Featured Application: One of the major problems which we faced in this century was energy shortage, Salix carbon-based solid acid catalyst is a promising method for preparing biodiesel with low-cost catalysts to alleviate the energy crisis.

\begin{abstract}
Salix carboniferous solid acid catalysts were successfully obtained via one-step carbonization and sulfonation of Salix psammophila in the presence of concentrated sulfuric acid, which was then used in the esterification reaction between oleic acid and methanol to prepare the biodiesel. The esterification rate of the catalyst obtained from the reaction indicated the catalytic performance of the catalyst. Afterwards, the recycling performance of the catalyst was optimized and characterized based on Fourier transform infrared spectrometer. The catalyst performance was examined and optimized through the response surface method, and the catalyst was determined and characterized based on scanning electron microscope (SEM), elemental analysis, thermogravimetric analysis, and infrared analysis. The results suggested that the optimal preparation conditions were as follows: reaction temperature of $125^{\circ} \mathrm{C}$, reaction time of $102 \mathrm{~min}$, solid-liquid ratio of $17 \mathrm{~g} / 100 \mathrm{~mL}$, standing time of $30 \mathrm{~min}$, and the highest conversion level of $94.15 \%$.
\end{abstract}

Keywords: one-step method; carbonized sulfonation; response surface method; Salix carboniferous solid acid catalysts; biodiesel

\section{Introduction}

Nowadays, oil is the most important source of energy worldwide, but the emissions of greenhouse gases threaten the global ecosystem and sustainable resources have become an urgent need in our daily life [1]. The increasing scarcity of fossil fuels and the emissions of greenhouse gases and related climate change are the main driving forces to develop clean energy [2-4]. Biodiesel is a clean fuel energy consisting of $\mathrm{C}_{12}-\mathrm{C}_{22}$ fatty acids, which are a kind of long-chain fatty acid alkyl. Compared to fossil fuel, biodiesel shows the advantages of being a biodegradable, sulfur-free, and non-toxic sustainable diesel fuel substitute [5]. Biodiesel can be prepared through the transesterification or esterification of the raw materials of various animal and plant fats, as well as waste oils or vegetable oleic acid with low carbon-chain alcohol [6-9]. Concentrated sulfuric acid is the most extensively used catalyst in the preparation of biodiesel, which can hardly be separated from the products and eventually leads to corrosion of equipment and severe environmental pollution. Therefore, it is of great practical significance to investigate and develop the cheap and environmentally friendly catalyst. The solid acid catalyst is mostly inorganic, including the metal oxides, metal sulfates, metal phosphates, zeolites, etc., which are beginning to appear. However, to some extent, the poor applicability of inorganic 
solid acid catalysts has limited their usage, especially in liquid phase reactions. The carbonation solid acid catalysts that have been intensively studied in recent years have largely solved these problems. Since 2004, the research group of Toda [10] first used polycyclic aromatic compounds as raw materials, and carbonized the material at $400{ }^{\circ} \mathrm{C}$ to obtain powdery products between amorphous carbon and incomplete carbonization. Then the products were reacted in a certain amount with concentrated sulfuric acid at $150{ }^{\circ} \mathrm{C}$ for a certain period of time to obtain sulfonated carbonation solid acid catalysts, which were applied to the catalytic esterification reaction. The carbonation solid acid catalysts have become promising catalysts. Many countries have studied and prepared different carbon-based solid acid catalysts. There are also more and more examples of esterification reactions. Lou et al. [11] prepared carbonation solid acid catalysts from four different raw materials, among which starch had the highest catalytic activity, which is higher than $\mathrm{SO}_{4}{ }^{2-} / \mathrm{ZrO}_{2}$ and niobic acid. Zong et al. [12] prepared carbonation solid acid catalysts of type $\mathrm{CH}_{1.14} \mathrm{~S}_{0.03} \mathrm{O}_{0.39}$ with D-glucose powder. The acid strength of the catalysts corresponds to the acid strength of concentrated sulfuric acid. XRD analysis showed that the glucose carbonation solid acid catalysts had an amorphous structure. Kastner et al. [13] used two kinds of biomass, namely peanut shell and wood chips, as raw materials, which were cracked, carbonized, and mixed with concentrated sulfuric acid for sulfonation to obtain biomass carbonation solid acid catalysts. The catalysts have high catalytic activity in the catalytic esterification of palmitic acid and stearic acid, as well as remarkable stability.

As a highly abundant, natural carbon source, biomass is considered as a promising renewable source alternative to fossil fuels [14-17]. The utilization of waste biomass to prepare the biomass carboniferous solid acid catalyst exerts a win-win effect on both the economy and environment [18-23]. Salix psammophila is a characteristic plant in Inner Mongolia, and every year the even stubble rejuvenation products become the agricultural and forest residues [24-26]. Using cheap Salix psammophila as the raw material, the one-step carbonation and sulfonation of concentrated sulfuric acid was used to prepare the Salix carboniferous solid acid catalyst, with the biodiesel prepared by oleic acid and methanol. The catalyst preparation conditions were optimized using the response surface method. Based on the advantages of special resources in Inner Mongolia, we not only realize the new energy utilization of sandy shrubs, but also strive to obtain new catalytic materials of Salix carboniferous solid acid catalysts with excellent catalytic performance to improve biodiesel production.

\section{Materials and Methods}

\subsection{Materials}

Salix was collected from a local supermarket in Ordos. (Inner Mongolia Autonomous Region, China). Concentrated Sulfuric Acid (98\%, Analytical Pure) was provided by Sinopharm Chemical Reagent Co., Ltd. (Shanghai, China). Ethanol (95\%, Analytical Pure) was purchased from Tianjin Fengchuan Chemical Reagent Science and Technology Co., Ltd. (Tianjin, China). Cis-9-octadecenoic acid (99\%, Analytical Pure) was provided by Tianjin Fuchen Chemical Reagent Factory (Tianjin, China). Absolute methanol (99\%, Analytical Pure) was purchased from Tianjin Fengchuan Chemical Reagent Science and Technology Co., Ltd. (Tianjin, China).

\subsection{Methods}

The Salix psammophila was smashed and filtered with a 50-80 mesh sieve, then a certain mass of Salix psammophila powder was weighed and put into the polytetrafluoroethylene (PTFE) reactor, and different volumes of concentrated sulfuric acid were added at different solid-liquid ratios. After standing for a certain period of time, the reactor body was put into the homogeneous reactor, a certain temperature was adjusted to react under rotation for a certain period of time, and the reactor was then taken out and put into ice water for sudden cooling. The cooled solid-liquid mixture was added into $300 \mathrm{~mL}$ distilled water, stirred, filtered, and washed repeatedly with hot distilled water until it 
had become neutral. Afterwards, the mixture was dried for $24 \mathrm{~h}$ in the oven at $100{ }^{\circ} \mathrm{C}$, then ground, packaged into a seal bag, labeled, and stored in the dryer for use.

A certain amount of oleic acid, methanol, and Salix carboniferous solid acid catalyst were added into a 3-neck flask (the quality of catalyst: the quality of oleic acid $=7 \%$, the amount of substance of methanol: the amount of substance of oleic acid $=10: 1)$, which was then put into a water bath at a certain temperature $\left(68 \pm 1{ }^{\circ} \mathrm{C}\right)$, and a reflux condenser was placed on the top of the 3-neck flask. After reaching the reaction temperature, the reaction time was counted when liquid reflux was observed in the reflux condensing tube above. After reaching the designated reaction time, the 3-neck flask was taken out and cooled rapidly. The solid acid catalyst was washed with ethanol, and the aqueous phase in the filtrate was evaporated using the rotatory evaporator to obtain the mixture of methyl oleate and oleic acid, which was then titrated.

According to the determination of animal and plant fat acid value and acidity through the third method of hot ethanol method in GB 5009.229-2016, the mixture was dissolved into $50 \mathrm{~mL}$ of $95 \%$ ethanol, which was heated through a water bath and titrated using the $0.1 \mathrm{~mol} / \mathrm{L} \mathrm{KOH}$ standard solution, with phenolphthalein as the indicator. The titration end-point was reached when the solution became light red and did not fade within $1 \mathrm{~min}$, and the oleic acid conversion rate, namely, the conversion level $(X)$, was calculated.

$$
X=\left(A_{0}-A_{\mathrm{T}}\right) / A_{0} \times 100 \%
$$

where $A_{0}$ is the initial acid value of the reaction $(\mathrm{mmol} / \mathrm{g})$, and $A_{\mathrm{T}}$ is the instantaneous acid value of the reaction $(\mathrm{mmol} / \mathrm{g})$.

The Box-Behnken four-factor three-level response surface method (RSM) design method was utilized, among which, reaction temperature, reaction time, solid-liquid ratio, and standing time were treated as the independent variables, while conversion level was considered as the response value. The factors and level coding are presented in Table 1. In total, 9 experiments (including 4 analytical experiments and 5 central experiments) were designed to estimate the experimental error. The response curve experimental design and results are displayed in Table 2. The Design-Expert software was used for analysis, and the following response surface model was constructed.

$$
\begin{gathered}
X=88.24+1.17 A+0.49 B-2.53 C-1.01 D-3.02 A B+4.60 A C+2.47 A D+2.28 C- \\
2.27 B+4.41 C D-5.65 A^{2}-2.92 B^{2}-1.68 C^{2}-1.47 D^{2}
\end{gathered}
$$

Table 1. Factor levels for the experiments.

\begin{tabular}{ccccc}
\hline Levels & $\begin{array}{c}\text { A: Reaction } \\
\text { Temperature/ }\end{array}{ }^{\circ} \mathbf{C}$ & $\begin{array}{c}\text { B: Reaction } \\
\text { Time/min }\end{array}$ & $\begin{array}{c}\text { C: Solid-Liquid } \\
\text { Ratio }\end{array}$ & $\begin{array}{c}\text { D: Standing } \\
\text { Time/min }\end{array}$ \\
\hline-1 & 120 & 60 & $1: 4$ & 30 \\
0 & 135 & 90 & $1: 5$ & 60 \\
1 & 150 & 120 & $1: 6$ & 90 \\
\hline
\end{tabular}


Table 2. Design of RSM and its experimental values.

\begin{tabular}{|c|c|c|c|c|c|}
\hline Number & $\begin{array}{c}\text { A: Reaction } \\
\text { Temperature } /{ }^{\circ} \mathrm{C}\end{array}$ & $\begin{array}{l}\text { B: Reaction } \\
\text { Time/min }\end{array}$ & $\begin{array}{c}\text { C: } \\
\text { Solid-Liquid } \\
\text { Ratio }\end{array}$ & $\begin{array}{l}\text { D: Standing } \\
\text { Time/min }\end{array}$ & $\begin{array}{l}\text { Conversion } \\
\text { Level/\% }\end{array}$ \\
\hline 1 & 135 & 120 & $1: 5$ & 30 & 83.19 \\
\hline 2 & 135 & 90 & $1: 6$ & 30 & 89.98 \\
\hline 3 & 135 & 90 & $1: 5$ & 60 & 86.69 \\
\hline 4 & 135 & 60 & $1: 5$ & 30 & 84.01 \\
\hline 5 & 135 & 60 & $1: 6$ & 60 & 86.04 \\
\hline 6 & 150 & 90 & $1: 5$ & 90 & 78.93 \\
\hline 7 & 150 & 120 & $1: 5$ & 60 & 81.71 \\
\hline 8 & 120 & 90 & $1: 4$ & 60 & 74.49 \\
\hline 9 & 135 & 120 & $1: 4$ & 60 & 85.89 \\
\hline 10 & 135 & 90 & $1: 6$ & 90 & 84.67 \\
\hline 11 & 135 & 120 & $1: 5$ & 90 & 79.61 \\
\hline 12 & 150 & 60 & $1: 5$ & 60 & 84.15 \\
\hline 13 & 150 & 90 & $1: 5$ & 30 & 84.51 \\
\hline 14 & 120 & 90 & $1: 6$ & 60 & 88.97 \\
\hline 15 & 135 & 120 & $1: 6$ & 60 & 86.20 \\
\hline 16 & 120 & 90 & $1: 5$ & 30 & 88.33 \\
\hline 17 & 135 & 90 & $1: 5$ & 60 & 87.33 \\
\hline 18 & 150 & 90 & $1: 4$ & 60 & 82.53 \\
\hline 19 & 120 & 120 & $1: 5$ & 60 & 80.70 \\
\hline 20 & 150 & 90 & $1: 6$ & 60 & 78.60 \\
\hline 21 & 135 & 90 & $1: 5$ & 60 & 85.98 \\
\hline 22 & 135 & 90 & $1: 5$ & 60 & 90.27 \\
\hline 23 & 135 & 60 & $1: 4$ & 60 & 76.60 \\
\hline 24 & 120 & 90 & $1: 5$ & 90 & 72.86 \\
\hline 25 & 120 & 60 & $1: 5$ & 60 & 71.05 \\
\hline 26 & 135 & 60 & $1: 5$ & 90 & 89.51 \\
\hline 27 & 135 & 90 & $1: 4$ & 90 & 88.49 \\
\hline 28 & 135 & 90 & $1: 5$ & 60 & 90.93 \\
\hline 29 & 135 & 90 & $1: 4$ & 30 & 76.14 \\
\hline
\end{tabular}

\section{Results and Discussion}

The regression model analysis of variance is shown in Table 3. The regression parameters of the response surface were analyzed through Analysis of Variance. The F-test was conducted to evaluate the significance of the influence of variables in the regression equation on the response value. Typically, a smaller probability $P$ ( $P$-Value) is associated with a higher significance of the corresponding variable. In the proposed model, $P=0.0406<0.05$, and the response surface regression model reached a significant level; while the lack of fit was $P=0.0873>0.05$, which was not significant, suggesting that all experimental points were expressed using the model, high degree of fitting was achieved, and the regression equation model was successfully established. These findings demonstrate that, the Salix carbon-based solid acid catalyst can well catalyze the preparation of biodiesel. Among the linear terms, the solid-liquid ratio $C$ had the greatest influence $P=0.0486<0.05$, ranking a significant level. Among the quadratic terms, reaction temperature $\mathrm{A}^{2}(P=0.0032<0.01)$ reached an extremely significant level and the interaction terms $P_{A C}=0.0394$ (significant level of model in reaction temperature and solid-liquid ratio factors) and $P_{C D}=0.0469$ (significant level of model in solid-liquid ratio and standing time factors) exerted significant influence on the catalyst performance $(P<0.05)$. Within the range of each factor selected in the present study, the solid-liquid ratio had the greatest influence on the catalytic performance of the Salix carboniferous solid acid catalyst. 
Table 3. Results of variance analysis of regression models.

\begin{tabular}{|c|c|c|c|c|c|c|}
\hline Source Model & $\begin{array}{l}\text { Sum of } \\
\text { Squares }\end{array}$ & $\begin{array}{l}\text { Degrees } \\
\text { Freedom }\end{array}$ & $\begin{array}{l}\text { Mean } \\
\text { Square }\end{array}$ & F-Value & $\begin{array}{c}P \text {-Value }> \\
\text { F-Value }\end{array}$ & $\begin{array}{c}\text { Significant } \\
\text { Level }\end{array}$ \\
\hline model & 603.943 & 14 & 43.139 & 2.6279 & 0.041 & significant \\
\hline A & 16.4034 & 1 & 16.403 & 0.9993 & 0.335 & \\
\hline $\mathrm{B}$ & 2.9403 & 1 & 2.940 & 0.1791 & 0.679 & \\
\hline $\mathrm{C}$ & 76.6085 & 1 & 76.609 & 4.6669 & 0.049 & significant \\
\hline $\mathrm{D}$ & 12.1807 & 1 & 12.181 & 0.7420 & 0.404 & \\
\hline $\mathrm{AB}$ & 36.5420 & 1 & 36.542 & 2.2261 & 0.158 & \\
\hline $\mathrm{AC}$ & 84.7320 & 1 & 84.732 & 5.1617 & 0.039 & significant \\
\hline $\mathrm{AD}$ & 24.4530 & 1 & 24.453 & 1.4896 & 0.242 & \\
\hline $\mathrm{BC}$ & 20.8392 & 1 & 20.839 & 1.2695 & 0.279 & \\
\hline $\mathrm{BD}$ & 20.6116 & 1 & 20.612 & 1.2556 & 0.281 & \\
\hline $\mathrm{CD}$ & 77.9689 & 1 & 77.969 & 4.7497 & 0.047 & significant \\
\hline $\mathrm{A}^{2}$ & 206.912 & 1 & 206.91 & 12.605 & 0.003 & significant \\
\hline $\mathrm{B}^{2}$ & 55.2748 & 1 & 55.275 & 3.3672 & 0.088 & \\
\hline$C^{2}$ & 18.2349 & 1 & 18.235 & 1.1108 & 0.310 & \\
\hline $\mathrm{D}^{2}$ & 14.0723 & 1 & 14.072 & 0.8573 & 0.370 & \\
\hline Residual & 229.816 & 14 & 16.415 & & & \\
\hline Lack of Fit & 210.121 & 10 & 21.012 & 4.2675 & 0.087 & $\begin{array}{c}\text { not } \\
\text { significant }\end{array}$ \\
\hline Pure Error & 19.6952 & 4 & 4.924 & & & \\
\hline Cor Total & & 28 & & & & \\
\hline
\end{tabular}

A 3D diagram can represent not only the characters of the response surface function, but also intuitively illustrate the effect of interaction between factors on the response value.

As can be observed from Figure 1, the interactions between reaction temperature and the solid-liquid ratio, as well as the between standing time and solid-liquid ratio, are extremely significant. They are manifested by a relatively steep curve, verifying that the interactive items of reaction temperature, standing time, and solid-liquid ratio exert significant influence on the catalytic activity of the catalyst.
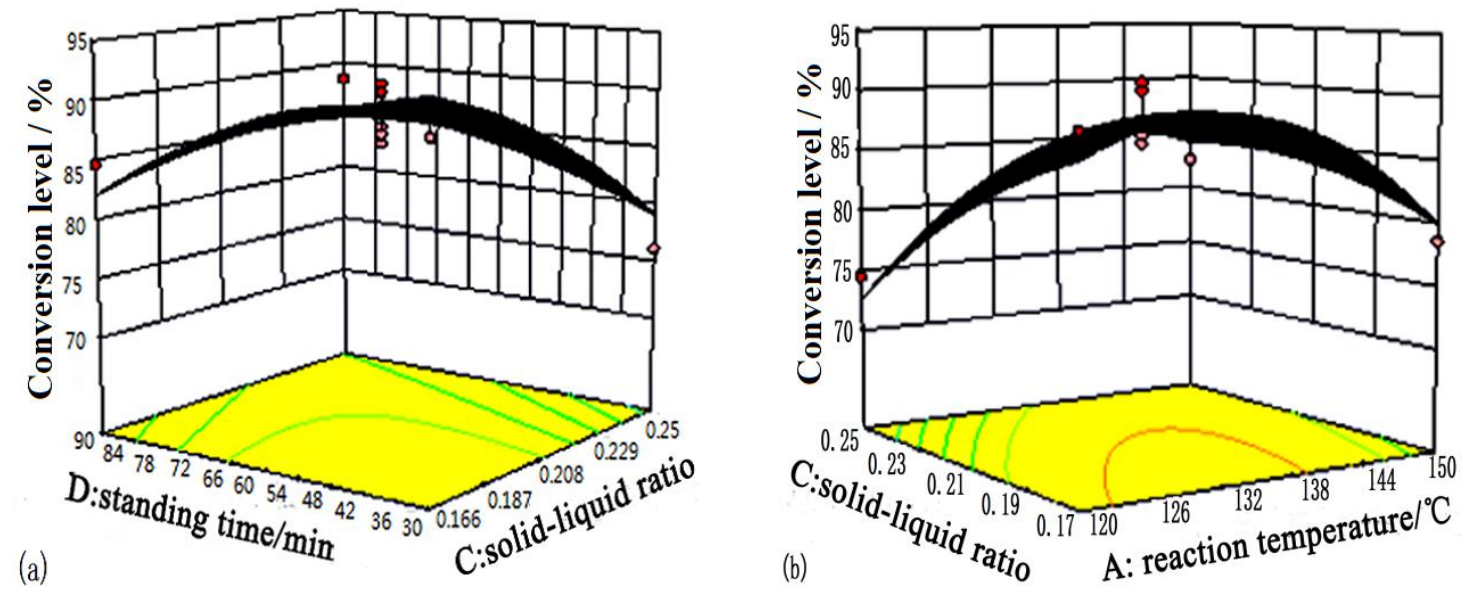

Figure 1. (a) Response surface diagram of the effect of solid-liquid ratio and standing time interaction on conversion level; (b) response surface diagram of the effects of reaction temperature and solid-liquid ratio interaction on conversion level.

According to Figure 2a, when the reaction temperature remains unchanged, the conversion level shows an increasing trend with an extension in reaction time, and the catalyst activity is enhanced. When the reaction time remains unchanged, the conversion level also displays an increasing trend with the increase in reaction temperature. In linear terms, reaction time and reaction temperature 
make basically the same influence on the catalyst. Figure $2 b$ shows that with the reaction temperature remaining unchanged, the conversion level presents a decreasing trend with an increase in standing time, and the catalyst activity is weakened; when the standing time remains unchanged, the conversion level is first increased and then decreased with the increase in reaction temperature.
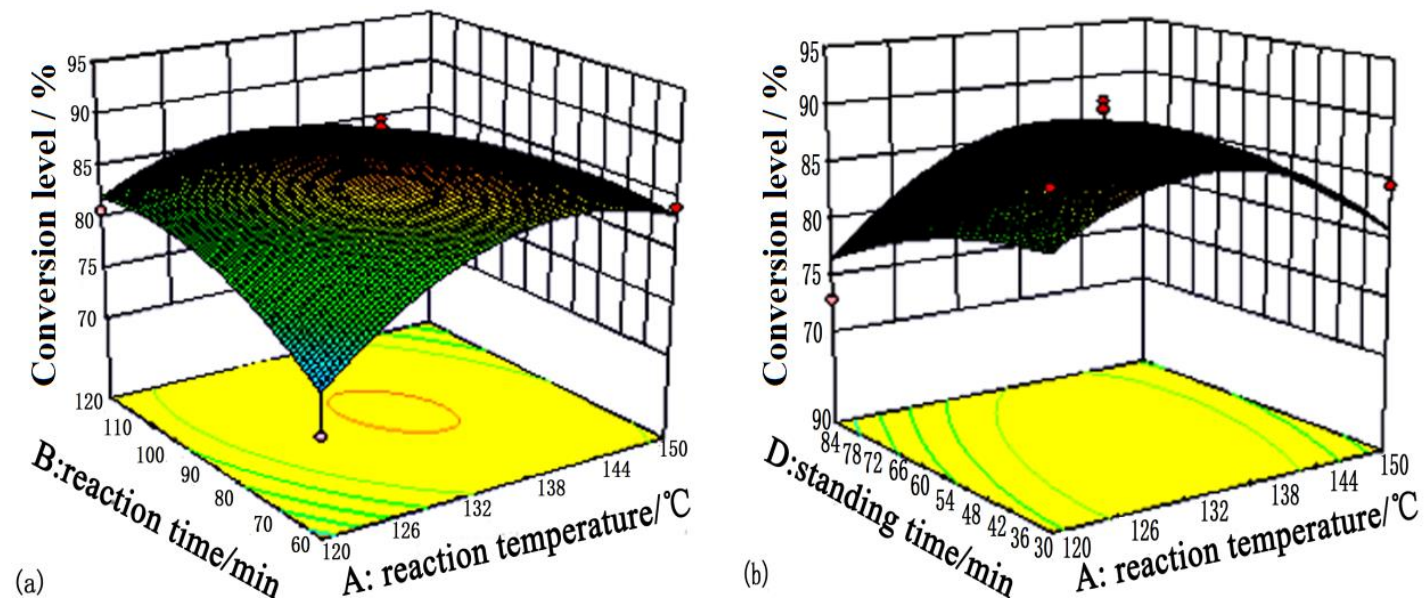

Figure 2. (a) Response surface diagram of the effect of reaction temperature, reaction time interaction on conversion level; (b) response surface diagram of the effect of reaction temperature, standing time interaction on conversion level.

As can be observed from Figure 3a, with a constant reaction time, the conversion level shows an increasing trend with the increase of concentrated sulfuric acid in solid-liquid ratio, and the catalyst activity is also enhanced. When the solid-liquid ratio remains unchanged, the conversion level is relatively gentle with the increase in reaction time. Among the linear terms, solid-liquid ratio has more significant influence than reaction temperature on the catalyst. As presented in Figure $3 b$, under the condition that the standing time remains unchanged, the conversion level shows an increasing trend with the extension in reaction time, and the catalyst activity is promoted. When the reaction time is unchanged, the conversion level also displays an increasing trend with the increase in standing time.
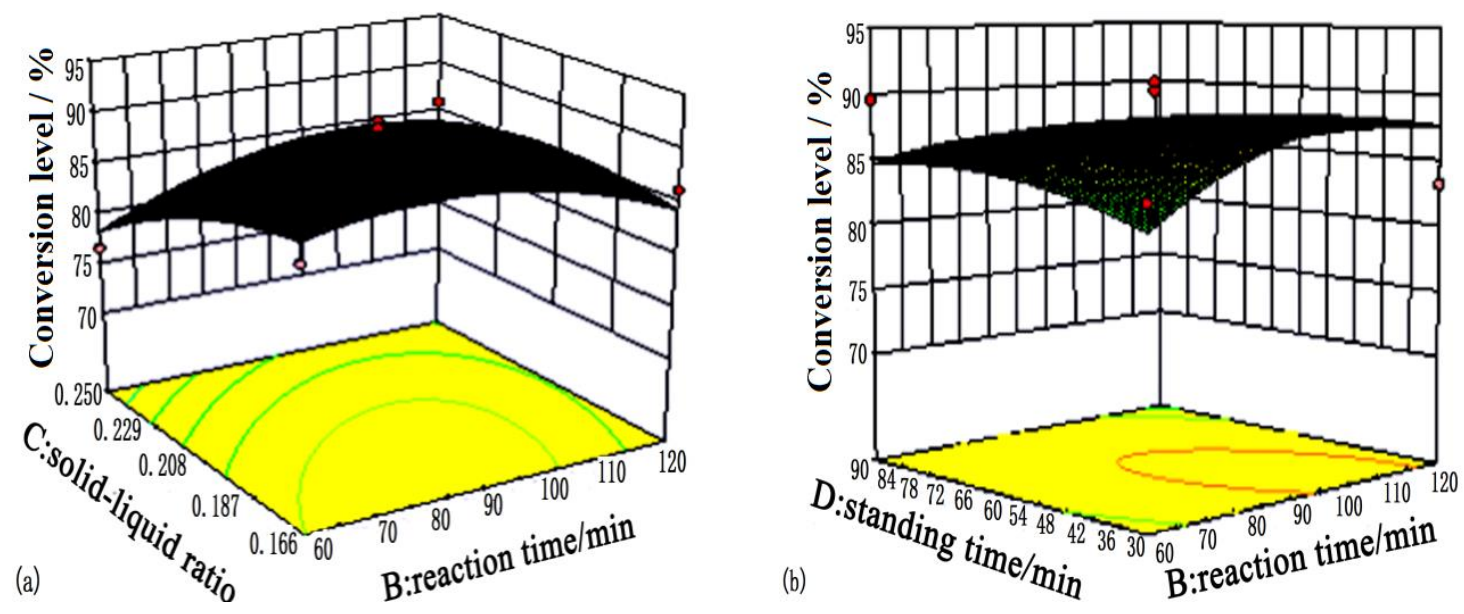

Figure 3. (a) Response surface diagram of the effect of solid-liquid ratio and reaction time interaction on conversion level; (b) response surface diagram of the effect of standing time and reaction time interaction on conversion level.

The maximum response value maximum was determined using the numerical function of Design-Expert software, and the optimal reaction conditions are obtained as follows: reaction 
temperature of $125^{\circ} \mathrm{C}$, reaction time of $102 \mathrm{~min}$, solid-liquid ratio of $17 \mathrm{~g} / 100 \mathrm{~mL}$, standing time of $30 \mathrm{~min}$, and highest conversion level of $95 \%$.

After optimization with the above-mentioned software, the above conditions were employed to verify the experiment. The conversion level of esterification reaction for the preparation of biodiesel catalyzed by the Salix carbon-based solid acid catalyst was $94.15 \%$. The relative deviation between the software predicted value and the experimental value was $0.89 \%$. Therefore, it is feasible to employ this model to analyze and predict the catalytic performance of the Salix carboniferous solid acid catalyst.

When comparing (Table 4), the contents of $\mathrm{C}, \mathrm{O}$, and $\mathrm{H}$ in Salix psammophila raw materials were $51.886 \%, 41.348 \%$, and $6.316 \%$, respectively. The contents of $\mathrm{N}$ and $\mathrm{S}$ were lower, which were $0.31 \%$ and $0.14 \%$, respectively. After the one-step method, the content of $\mathrm{N}$ was not obvious, while the content of $\mathrm{O}$ and $\mathrm{H}$ were significantly decreased, which was caused by the precipitation of $\mathrm{O}$ and $\mathrm{H}$ on a part of the aromatic ring in the reaction substituted by the sulfonic acid group. The content of $S$ in the catalyst was obviously increased to $26.378 \%$ and the measured surface acid amount was $1.28 \mathrm{mmol} / \mathrm{g}$, indicating that the $\mathrm{S}$ was introduced into the raw materials of Salix, and the sulfonic acid group was formed.

Table 4. Elemental analysis.

\begin{tabular}{cccccc}
\hline & $\mathbf{C}$ & $\mathbf{H}$ & $\mathbf{N}$ & $\mathbf{O}$ & $\mathbf{S}$ \\
\hline Salix psammophila & $51.886 \%$ & $6.316 \%$ & $0.31 \%$ & $41.348 \%$ & $0.14 \%$ \\
Catalyst & $50.122 \%$ & $7.583 \%$ & $0.293 \%$ & $15.624 \%$ & $26.378 \%$ \\
\hline
\end{tabular}

As shown, Figure 4 presents that in the infrared spectrum peak of the catalyst, the solid acid catalysts prepared by the one-step method still had a peak of $3400 \mathrm{~cm}^{-1}$ containing the associated hydroxyl group and the stretching vibration of the hydroxyl group contained in the carboxyl group; the carbonyl peak contained in the carboxyl group at $1600 \mathrm{~cm}^{-1}$; the stretching vibration peaks of $\mathrm{SO}_{3} \mathrm{H}$ and $\mathrm{O}=\mathrm{S}=\mathrm{O}$ bonds occur at about $1000 \mathrm{~cm}^{-1}$ and $1100 \mathrm{~cm}^{-1}$, respectively, demonstrating that concentrated sulfuric acid has played a role in sulfonation and the sulfonyl has been successfully introduced after the one-step method treatment of Salix psammophila. In the one-step process of concentrated sulfuric acid, the positively charged sulfonic acid group electrophilically replaced $C$ on the fused ring structure to form a sulfonic acid complex intermediate. After deprotonation, a carbon-based solid acid catalyst with three acidic groups, $\mathrm{SO}_{3} \mathrm{H}, \mathrm{OH}$, and $\mathrm{COOH}$ were formed, in which a sulfonic acid group was grafted on a carbon skeleton of a polycyclic aromatic carbon ring arranged in a disorderly manner.
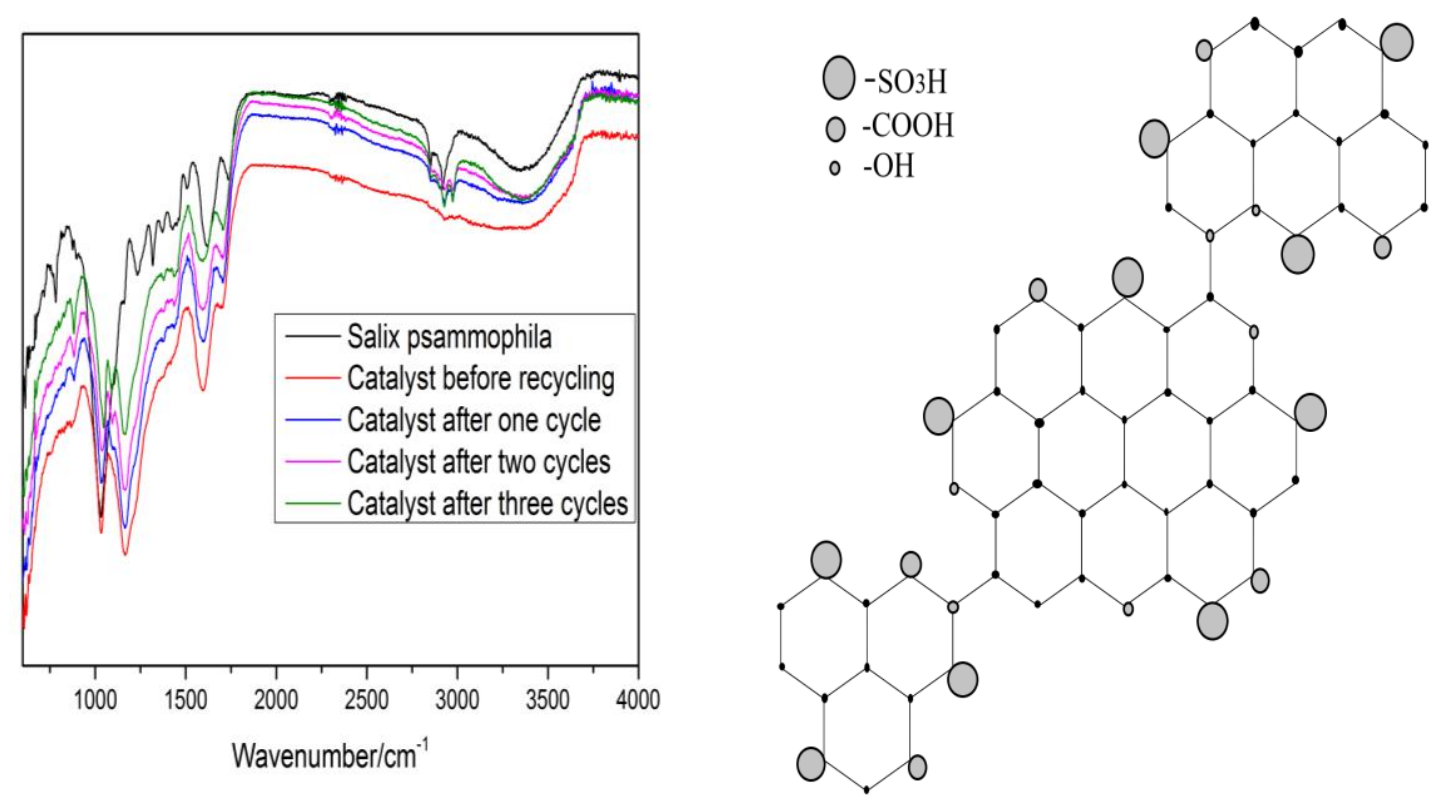

Figure 4. Infrared spectra and syntactic model of catalysts. 
Simultaneously, Figure 4 shows that the infrared spectrum peak image of the Salix carboniferous solid acid catalyst prepared under the optimal conditions were reused after washing with hot distilled water. The change of conversion level after four cycles is as follows: $92.35 \%, 76.23 \%, 74.22 \%, 75.73 \%$. The methyl oleate absorption peak could be observed at $3000 \mathrm{~cm}^{-1}$, while the catalytic activity of catalyst had decreased, to a large extent, caused by the effect of coating of the catalyst with methyl oleate. The conversion level of catalytic biodiesel reaction was obviously improved by changing the washing liquid of the catalyst, soaking in ethanol solution, and repeatedly washing with hot ethanol solution. The change of conversion level after four cycles is as follows: $92.35 \%, 87.28 \%, 84.74 \%, 85.36 \%$.

Figure 5 shows the thermogravimetry (TG)-derivative thermogravimetry (DTG) curve of the catalyst under $\mathrm{N}_{2}$ atmosphere at the heating rate of $20^{\circ} \mathrm{C} / \mathrm{min}$ and an ending temperature of $800{ }^{\circ} \mathrm{C}$. The catalyst dehydration phase occurred at about $105^{\circ} \mathrm{C}$, and the first weight loss rate peak occurred in the DTG curve, and the TG curve showed that the weight loss ratio was $3.73 \%$. The catalyst thermolysis phase occurred at about $180-280^{\circ} \mathrm{C}$. The second weight loss rate peak could be observed in the DTG curve, and the TG curve showed that the weight loss ratio was $5.12 \%$. The weight loss rate peak of the DTG curve at $290^{\circ} \mathrm{C}$ was consistent with the peak shape of the experimental initial current instability, which proves that the peak appears to be related to the instrument current instability. The figure presented that the catalyst had been obviously decomposed at $238{ }^{\circ} \mathrm{C}$, which indicated excellent thermal stability.

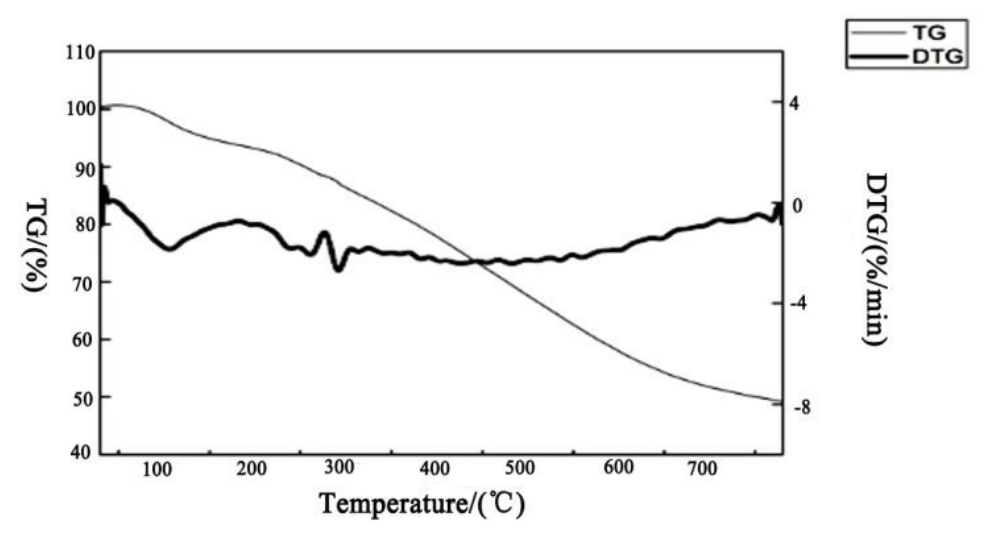

Figure 5. Thermogravimetry -derivative thermogravimetry curve of catalyst.

In the scanning electron micrograph of Figure 6, the left picture shows the Salix psammophila and the right picture shows the catalyst prepared under the optimal conditions. As can be observed, under the same scanning electron microscope conditions, when the scale is 5 microns, the structure of Salix psammophila is greatly damaged compared with the catalyst. The water molecules and organic ingredients contained in the Salix psammophila at the one-step method were evaporated, and the catalyst surface showed the porous frame structure. Meanwhile, the space was mainly filled with the amorphous carbon particles with irregular shapes, and these carbon particles were arranged in a spherical structure. In the field of view, the surface of the sand willow is relatively smooth, while the surface of the catalyst is rough. The particles have showed obvious brightness and darkness, which may be caused by the introduction of sulfonic acid groups or the different particle positions. 


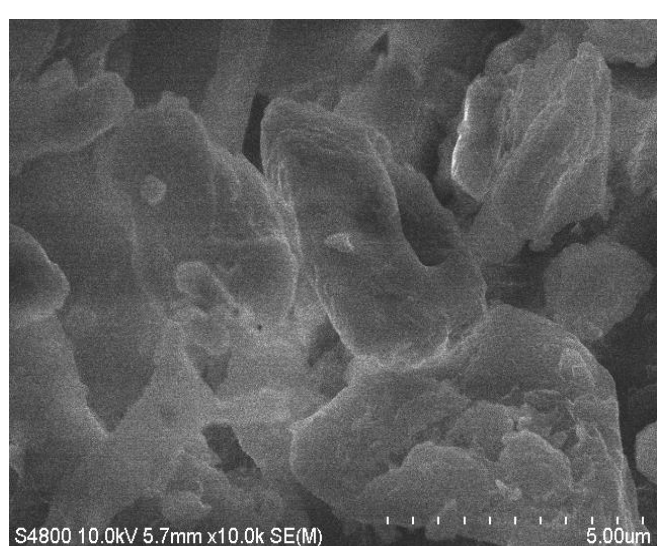

(a)

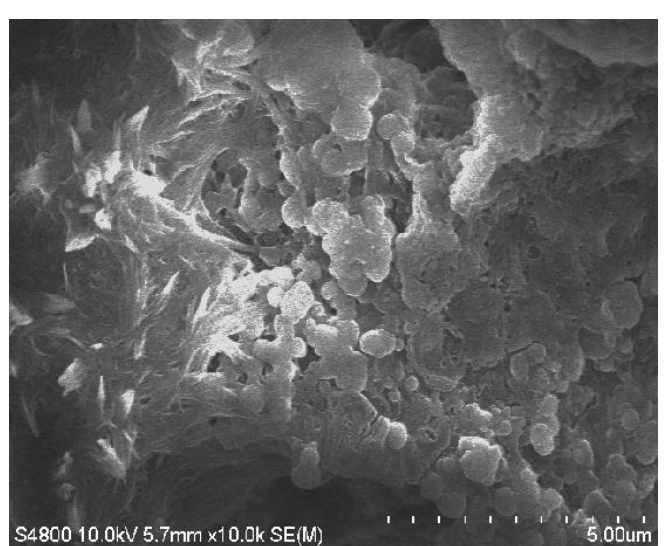

(b)

Figure 6. (a) Scanning electron micrographs of Salix psammophila; (b) Scanning electron micrographs of the catalyst.

In the catalyst reaction mechanism of Figure 7, the Salix carboniferous solid acid catalysts provide $\mathrm{H}^{+}$, which formed a monomolecular carbocation with the oxygen on the carbonyl group in the oleic acid structure. Then the hydroxyl group on the methanol attacks the carbonyl group on the oleic acid to form a nucleophilic addition reaction. The intermediate is obtained, which is extremely unstable. After reversible rearrangement, the water molecule is lost as a leaving group, and finally methyl oleate is formed.

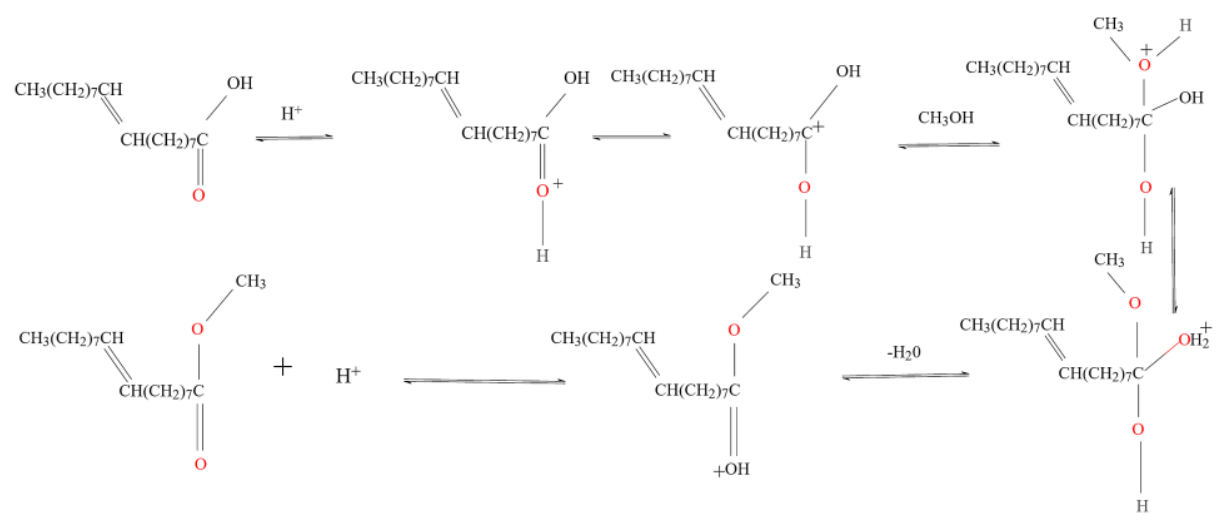

Figure 7. Mechanism of catalyst participation in esterification.

\section{Conclusions}

Salix carboniferous solid acid catalysts were prepared from waste biomass Salix psammophila of Inner Mongolia shrub in one step by using the dehydration and acidity of concentrated sulfuric acid and a low-cost reduction method. The response surface curve analysis was carried out using a large amount of experimental data, and the data model was established. The experiment was combined with the data simulation to further optimize the activity of the Salix carboniferous solid acid catalysts.

The one-step carbonation and sulfonation could effectively introduce the sulfonic acid group. Through the test of catalyst recycling, it was concluded that the coating of methyl oleate on catalyst is the main factor affecting the effect of catalytic recycling. Through the combination of experimental optimization and test characterization, the relationship between the structural characteristics of the catalyst and the mechanism of the catalyst in the catalytic reaction was explored, and the obtained catalyst had good activity, stability and application value.

Author Contributions: P.L. conceived, designed, performed the experiments, analyzed the data, and wrote the paper; J.G. taught software to process the data; K.W. revised the manuscript. 
Funding: This research was funded by the National Nature Science Foundation of China $(21,366,018)$, Key Research.

Conflicts of Interest: The authors declare no conflicts of interest.

\section{References}

1. Walter, B.; Gruson, J.F.; Monnier, G. Motorisation Et Carburants Diesel: Un Large Spectre D'évolutions À Venir Contexte Général Et Thématiques De Recherche. Oil Gas Sci. Technol. 2008, 63, 387-393.

2. Luque, R.; Lovett, J.C.; Datta, B.; Clancy, J.; Campelo, J.M.; Romero, A.A. Biodiesel as feasible petrol fuel replacement: A multidisciplinary overview. Energy Environ. Sci. 2010, 3, 1706-1721. [CrossRef]

3. Wilson, K.; Lee, A.F. ChemInform Abstract: Rational Design of Heterogeneous Catalysts for Biodiesel Synthesis. Catal. Sci. Technol. 2012, 2, 884-897. [CrossRef]

4. Sharma, Y.C.; Singh, B.; Korstad, J. Advancements in solid acid catalysts for ecofriendly and economically viable synthesis of biodiesel. Biofuels Bioprod. Biorefin. 2011, 5, 69-92. [CrossRef]

5. Lotero, E.; Liu, Y.; Lopez, D.E.; Suwannakarn, K.; Bruce, D.A.; Goodwin, J.G. Synthesis of Biodiesel via Acid Catalysis. Ind. Eng. Chem. Res. 2005, 44, 5353-5363. [CrossRef]

6. Koh, M.Y. A review of biodiesel production from Jatropha curcas L. Oil. Renew. Sustain. Energy Rev. 2011, 15, 2240-2251. [CrossRef]

7. Luque, R.; Clark, J.H. Biodiesel-Like biofuels from simultaneous. transesterification/esterification of waste oils with a biomass-derived solid acid catalyst. Chem CatChem 2015, 3, 594-597. [CrossRef]

8. Venkateswarulu, T.C.; Raviteja, C.V.; Prabhaker, K.V.; Babu, D.J.; Reddy, A.R.; Indira, M.; Venkatanarayana, A. A Review on Methods of Transesterification of Oils and Fats in Bio-diesel Formation. Int. J. ChemTech Res. 2014, 6, 974-4290.

9. Liu, H.A.; Bo, Y. Advances in the research of stillingia oil components as feedstock of biodiesel. Genom. Appl. Biol. 2010, 29, 402-408.

10. Masakuza, T.; Atsushi, T.; Kondo, J.N.; Okamura, M.; Hayashi, S.; Hara, M. Biodiesel made with sugar catalyst. Nature 2005, 438, 178-179.

11. Lou, W.Y.; Zong, M.H.; Duan, Z.Q. Efficient production of biodiesel from high free fatty acid-containing waste oils using various carbohydrate-derived solid acid catalysts. Bioresour. Technol. 2008, 99, 8752-8758. [CrossRef]

12. Zong, M.H.; Duan, Z.Q.; Lou, W.Y.; Smith, T.J.; Wu, H. Preparation of a sugar catalyst and its use for highly efficient production of biodiesel. Green Chem. 2007, 9, 434-437. [CrossRef]

13. Kastner, J.R.; Miller, J.; Geller, D.P.; Locklin, J.; Keith, L.H.; Johnson, T. Catalytic esterification of fatty acids using solid acid catalysts generated from biochar and activated carbon. Catal. Today 2012, 190, 122-132. [CrossRef]

14. Mika, L.T.; Cséfalvay, E.; Áron, N. Catalytic Conversion of Carbohydrates to Initial Platform Chemicals: Chemistry and Sustainability. Chem. Rev. 2018, 118, 505-613. [CrossRef]

15. Van de Vyver, S.; Geboers, J.; Jacobs, P.A.; Sels, B.F. Recent Advances in the Catalytic Conversion of Cellulose. ChemCatChem 2011, 3, 82-94. [CrossRef]

16. Dusselier, M.; Mascal, M.; Sels, B.F. Selective Catalysis for Renewable Feedstocks and Chemicals. In Top Chemical Opportunities from Carbohydrate Biomass: A Chemist's View Biorefinery; Nicholas, K.M., Ed.; Springer International Publishing: Berlin, Germany, 2014; Volume 353, pp. 1-40.

17. Geboers, J.A.; Van De Vyver, S.; Ooms, R.; Op De Beeck, B.; Jacobs, P.A.; Sels, B.F. Chemocatalytic conversion of cellulose: Opportunities, advances and pitfalls. Catal. Sci. Technol. 2011, 1, 714-726. [CrossRef]

18. Tuhy, .; Samoraj, M.; Michalak, I.; Chojnacka, K. The Application of Biosorption for Production of Micronutrient Fertilizers Based on Waste Biomass. Appl. Biochem. Biotechnol. 2014, 174, 1376-1392. [CrossRef]

19. Vamvuka, D. Bio-oil, solid and gaseous biofuels from biomass pyrolysis processes-An overview. Int. J. Energy Res. 2011, 35, 835-862. [CrossRef]

20. Sims, R.E.H. Bioenergy to mitigate for climate change and meet the needs of society, the economy and the environment. Mitig. Adapt. Strateg. Glob. Chang. 2003, 8, 349-370. [CrossRef]

21. Shu, Q.; Gao, J.; Nawaz, Z.; Liao, Y.; Wang, D.; Wang, J. Synthesis of biodiesel from waste vegetable oil with large amounts of free fatty acids using a carbon-based solid acid catalyst. Appl. Energy 2010, 87, 2589-2596. [CrossRef] 
22. Shu, Q.; Nawaz, Z.; Gao, J.; Liao, Y.; Zhang, Q.; Wang, D.; Wang, J. Synthesis of biodiesel from a model waste oil feedstock using a carbon-based solid acid catalyst: Reaction and separation. Bioresour. Technol. 2010, 101, 5374-5384. [CrossRef]

23. Dehkhoda, A.M.; West, A.H.; Ellis, N. Biochar based solid acid catalyst for biodiesel production. Appl. Catal. Gen. 2010, 382, 197-204. [CrossRef]

24. Zhang, X.F.; Wang, K.B.; Yan, X.L.; Zhao, Y.B.; Guo, X.M. Alcoholysis of Salix psammophila liquefaction. Sci. Technol. Rev. 2014, 32, 37-40.

25. Huang, J.T.; Gao, G.H. Analysis of NMR spectra on liquefied products from Salix psammophila and Caragana intermedia woods. Chem. Ind. For. Prod. 2009, 29, 101-104.

26. Liu, X.; Wan, Y.; Liu, P.; Zhao, L.; Zou, W. Optimization of process conditions for preparation of activated carbon from waste Salix psammophila and its adsorption behavior on fluoroquinolone antibiotics. Water Sci. Technol. J. Int. Assoc. Water Pollut. Res. 2018, 77, 2555. [CrossRef]

(C) 2019 by the authors. Licensee MDPI, Basel, Switzerland. This article is an open access article distributed under the terms and conditions of the Creative Commons Attribution (CC BY) license (http://creativecommons.org/licenses/by/4.0/). 